Document downloaded from:

http://hdl.handle.net/10251/67658

This paper must be cited as:

Seguí Gil, L.; Calabuig Jimenez, L.; Betoret Valls, N.; Fito Maupoey, P. (2015).

Physicochemical and antioxidant properties of non-refined sugarcane alternatives to white sugar. International Journal of Food Science and Technology. 50(12):2579-2588. doi:10.1111/ijfs.12926.

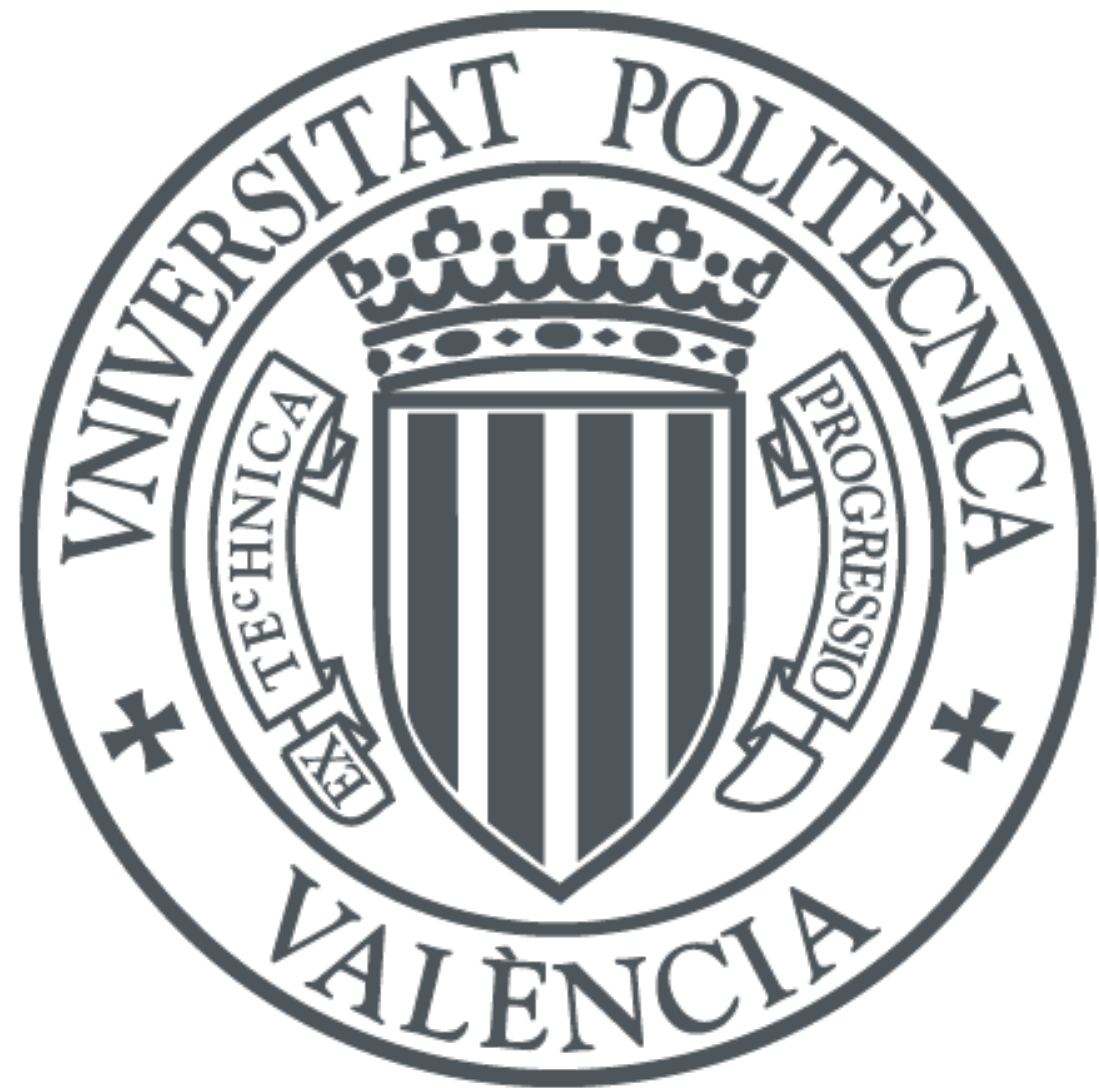

The final publication is available at

https://dx.doi.org/10.1111/ijfs.12926

Copyright Wiley

Additional Information 


\title{
PHYSICOCHEMICAL AND ANTIOXIDANT PROPERTIES OF NON- REFINED SUGARCANE ALTERNATIVES TO WHITE SUGAR
}

\author{
L. Seguí*, L. Calabuig-Jiménez, N. Betoret, P. Fito.
}

\section{Running title: Antioxidant properties of sugarcane products}

\author{
Instituto Universitario de Ingeniería de Alimentos para el Desarrollo. Universitat \\ Politècnica de València. Camino de Vera, s/n, Valencia 46022, Spain. \\ Tel.: (0034) 96 3877056; fax: (0034) 96 3877956. E-mail address: \\ lusegil@upvnet.upv.es
}

Keywords: sugars, sugarcane, jaggery, antioxidants, phenols, flavonoids.

\section{SUMMARY}

Antioxidant properties of commercial sugar cane derived products were analyzed to study their suitability for being used as functional ingredients. Cane honey, several jaggeries and several brown sugars were selected from the market and analyzed in terms of physicochemical characteristics and antioxidant properties, and compared with white refined sugar (12 products in total). Moisture, water activity, total soluble solids, $\mathrm{pH}$, color and sugar profile are reported. As for antioxidant properties, total phenols and flavonoid content, as well as antiradical ability (DPPH• and the TEAC-ABTS methods) are given. All sugarcane products contained phenols and flavonoids and exhibited in vitro antioxidant activity, determined by degree of refining. Among the alternatives analyzed, jaggeries and cane honey showed the best antioxidant properties. Thermal treatment did not significantly affect the antioxidant capacity of sugarcane products, especially jaggeries. Since sugar-rich products are widely consumed worldwide, the use of non-refined sugarcane derivatives in food formulation is encouraged.

\section{INTRODUCTION}

Table sugar, also known as white or refined sugar, is a white refined product extracted from sugar cane $(70 \%)$ or sugar beet (30\%), made of up to $99.9 \%$ of sucrose. Due to its high purity, its nutritional value is very poor and it is said to provide a high amount of "empty calories"; in addition, its consumption has also been related to a higher 
incidence of dental caries in occidental societies. Both aspects have contributed to the search of non-caloric and non-cariogenic alternatives such as sweeteners (Varzakas and Chryssanthopoulos, 2012). Nevertheless, despite the increase in sweeteners consumption and their use in food formulation, sugar continues to be an essential part of our diet, not only appreciated for its flavor and its particular sweetening characteristics, but also for its contribution to food preservation (Harish Nayaka et al., 2005). Refined sugar is the sugar most widely consumed in Europe and North America. However, apart from refined sugar, non-refined sugarcane alternatives are nowadays available in the market. According to Galloway (2000), non-centrifugal sugar used to be the dominant form of sugarcane consumption before the large-scale production of refined sugar after 1700. At present, these sugars are still commonly consumed in South-America, Asia and Africa, and they have experienced a significant increase in the European market. In fact, non-refined sugars have increased in quantity, diversity and availability, this being a consequence of both the increasing interest for natural food and ingredients, as well as of globalization, multiculturalism and immigration mainly from Asian and South American countries.

In Europe and North America sugar is mostly appreciated for its sweetening properties, whereas sugarcane has been part of traditional medicine in the tropics and subtropics where it is produced. As an example, it is used in Ayurvedic medicine to treat different heath problems such as infections, bronchitis, cough, anemia, constipation, jaundice, general debility and heart or blood conditions (Kadam et al., 2008). During the last years, sugarcane has raised interest regarding its nutraceutic properties. Several studies have shown beneficial effects of sugarcane extracts on models in vivo in the stimulation of the immune response, protection against liver damage, intestinal function recovery, protection against some infections, anti-trombotic and anti-stress effects or growth stimulation (Koge et al. 2001; Noa et al., 2002; El-Abasy et al., 2003, 2004; Amer et al., 2004; Lo et al., 2005; Motobu et al., 2006; Yamauchi et al., 2006). On searching the origin of these beneficial effects, it has been found that sugarcane has a powerful antioxidant activity (Feng et al., 2014; Abbas et al., 2014), and it is known that oxidative damage is involved in many human diseases such as cancer, cardiovascular diseases or other degenerative disorders. According to Kadam et al. (2008), the antioxidant properties of sugarcane juice could partially explain its therapeutic effects.

Antioxidant properties of sugarcane have been basically attributed to phenolic compounds, mainly flavonoids, phenolic acids and poliphenols. Food phenolic 
compounds, particularly flavonoids, are thought to play important roles in human health (Yao et al., 2004). However, these compounds are non-desired components in the sugar manufacturing process, and are eliminated from the juice during refining. Other sugarcane processed products, such as molasses, may contain other antioxidants components as a result of Maillard reactions developing during processing. Some studies have proved the antioxidant properties of raw sugarcane, residual molasses or their extracts. Among other beneficial effects, antiradical capacity, inhibition of lipid peroxidation, protection against oxidative and radiation induced DNA damage, and in vitro antiproliferative activity against cancer cell lines have been reported (DuarteAlmeida et al., 2007; 2006; Guimaraes et al., 2007; Kadam et al., 2008). Nevertheless, most studies have focused on identifying antioxidant components in sugarcane extracts and their potential health benefits, whereas less attention has been paid to the characterization of non-refined commercially available sugars. Yet, it seems plausible that non-refined sugarcane products may preserve some of the raw material properties, and these are likely to depend on the refining degree of each product. In recent years, some authors have reported the antioxidant activity of cane brown sugars and molasses (Payet et al., 2005; Phillips et al., 2009); Harish Nayaka et al. (2009) also included a jaggery sugar in their study.

At present, many non-refined sugarcane products are available in markets and supermarkets. In particular, we identified different kinds of brown sugars (coated, boiled, light to dark), several jaggeries (light to dark, granulated or in block) and sugarcane honey; each of which has undergone different processing, and may have been refined to a different extent. Despite available in many stores and supermarkets, consumption of these non-refined sugars is still marginal as compared with white sugar. Although sugarcane extracts have been suggested as therapeutic agents, the potential impact of non-refined cane sugars as a substitute for white sugar on formulated foods has not been evaluated yet.

In the present work, physicochemical and antioxidant properties of commercial sugarcane derived products are analyzed to study their suitability for being used as functional ingredients. As a healthier sweetener, non-refined cane sugars could be used as a substitute to white sugar in traditionally sugar-rich foods such as jams, syrups, pastries or desserts, but they could also be used to formulate new antioxidant-enriched products by using matrix engineering techniques such as osmotic dehydration or vacuum impregnation. 


\section{MATERIALS AND METHODS}

\subsection{Non-refined sugarcane products}

Supermarkets and specialized stores in Valencia (Spain) were visited so as to get a representative sample of the different non-refined cane sugars commercially available. Twelve products, including cane honey, several brown sugars, different jaggeries and white refined sugar, were selected for the study. Products were stored in dry conditions and at room temperature. The twelve selected products were: white sugar (W), used as reference material, coated brown sugar (CB), light brown sugar (LB), raw brown sugar (RB), dark brown sugar (DB), wet brown sugar (WB), raw brown sugar with molasses (MB), light jaggery block (LJ), regular jaggery block (RJ), granulated jaggery (GJ), dark jaggery block (DJ) and sugarcane honey $(\mathrm{CH})$.

\subsection{Physiochemical characterization}

Sugarcane products were analyzed in terms of moisture $\left(\mathrm{x}_{\mathrm{w}}\right)$, water activity $\left(\mathrm{a}_{\mathrm{w}}\right)$, total soluble solids (TSS), $\mathrm{pH}$, colour and sugar profile (fructose, glucose, sucrose). Moisture was determined with an infrared scale (AD-4714A, Afora SA) and water activity was measured with a hygrometer (Aqualab 4TE). Total soluble solids and $\mathrm{pH}$ were measured on 1:10 and 1:4 (w/w) solutions of the non-refined sugars, respectively. Total soluble solids were determined by refractometry (Brix degrees). The ICUMSA method (De Whalley, 1964) was used for colour analysis. This method measures the purity of the sugar by determining yellowness and it is considered the international official method for measuring crystallized white and brown sugars. It consists of measuring the absorbance at $420 \mathrm{~nm}$ of a solution of the sugar, after filtering the samples through nylon mesh $(0.45 \mu \mathrm{m})$. ICUMSA colour index (IC) is then calculated by the following equation, where Abs is the absorbance of the sample at $420 \mathrm{~nm}, \mathrm{~b}$ the light path length, and $\mathrm{c}$ the total solids content, obtained by refractometry (Brix degrees) and expressed in $\mathrm{g} / \mathrm{cm}^{3}$ by using density at $20{ }^{\circ} \mathrm{C}$.

$$
\mathrm{IC}=\frac{\mathrm{Abs}}{\mathrm{b} \cdot \mathrm{c}} \cdot 1000
$$

Fructose, glucose and sucrose content was determined by Ion Cromatography (HighPerformance Anion-Exchange Cromatography with Pulsed Amperometric Detector (HPAEC-PAD) (Cataldi et al., 2000). A 716 Compact IC Metrohm system and a 
Metrosep Carb 1 250/4.6 column (250 mmL x $4.6 \mathrm{mmID})$ were used; sodium hydroxide $0.1 \mathrm{M}$ being the mobile phase $(1 \mathrm{~mL} / \mathrm{min})$. Chromatograms were interpreted with the ICnet 2.0 software. Measurements were performed on filtered solutions $(0.45 \mu \mathrm{m})$ prepared at different concentrations (from 1.5:1,000 to 1:10,000 v/v) in deionized water. Fructose, glucose and sucrose standards ( $>99.5 \%$ purity) were purchased from SigmaAldrich.

\subsection{Determination of total phenols}

The total phenolic content of the non-refined sugar samples was measured using a modified colorimetric Folin-Ciocalteu method (Singleton et al., 1999; Wolfe et al., 2003). $0.125 \mathrm{~mL}$ of a $1: 4(\mathrm{w} / \mathrm{w})$ dilution of the samples were mixed with $0.5 \mathrm{~mL}$ of deionized water. Folin-Ciocalteu reagent $(0.125 \mathrm{~mL})$ was added to the solution and allowed to react for $6 \mathrm{~min}$. Then, $1.25 \mathrm{~mL}$ of a $7 \%$ sodium carbonate solution was added. Finally, the mixture was diluted to $3 \mathrm{~mL}$ with deionized water and colour was allowed to develop. After $90 \mathrm{~min}$, the absorbance of the mixture was read at $760 \mathrm{~nm}$ using a Helios Zeta UV/Vis (Thermo Scientific) spectrophotometer. Absorbance measurements were compared to a standard curve of gallic acid (purity $\geq 98 \%$, SigmaAldrich) and expressed as mg of gallic acid equivalents (GAE) per gram of product.

Sugars, mainly the reducing sugars glucose and fructose, may interfere in the FolinCiocalteu method by overestimating the amount of total phenolic compounds present in the sample (Slinkard \& Singleton, 1977; Singleton et al., 1999). In order to evaluate and eliminate this interference, several standard gallic acid curves were also prepared with different proportions of sugars (sucrose, glucose and fructose). The total amount of sugars in these calibrating curves was $25 \mathrm{~g} / 100 \mathrm{~mL}$ : curve A) $25 \%$ sucrose, $0 \%$ reducing sugars; curve B) 21\% sucrose, $4 \%$ reducing sugars; curve C) 19\% sucrose, $6 \%$ reducing sugars; curve D) $17 \%$ sucrose, $8 \%$ reducing sugars. When reducing sugars were added, similar amounts of glucose and fructose were used. Finally, five different calibration curves (A to D plus the original gallic acid curve) were obtained and were further used as appropriate to calculate the overestimation due to sugar presence in the samples.

\subsection{Determination of flavonoid content}

The flavonoid content of the non-refined sugars samples was measured using the colorimetric method of aluminum chloride (Luximon-Ramma et al., 2002). $1.5 \mathrm{~mL}$ of a 
diluted sample $(1: 25 \mathrm{w} / \mathrm{w})$ were mixed with $1.5 \mathrm{~mL}$ of aluminum chloride solution $(2 \%$ $\mathrm{w} / \mathrm{v}$ in methanol), the mixture was vigorously shaken and allowed to react for $10 \mathrm{~min}$. The absorbance at $368 \mathrm{~nm}$ of the mixture was then measured and compared to a standard curve of quercetin (purity $\geq 95 \%$, Sigma-Aldrich). The flavonoid content was expressed in $\mathrm{mg}$ of quercetin equivalents (QE) per gram of product.

\subsection{Quantification of antioxidant activity}

Antioxidant activity ( $\mathrm{AO}$ ) was assessed by determining the radical scavenging abilities of non-refined cane sugars using 1,1-diphenyl-2-picryl hydrazyl (DPPH•) and 2,20azobis-3-ethyl benzthiazoline-6-sulfonic acid (ABTS) methods.

The DPPH • method was based on the proposed by Brand-William et al. (1995) and consisted of diluting $30 \mu \mathrm{L}$ of the sample (i.e. different sugar solutions at concentrations from 1:4 to $1: 30 \mathrm{w} / \mathrm{v}$ ) in $970 \mu \mathrm{L}$ of methanol, and adding the mixture to $2 \mathrm{~mL}$ of a $\mathrm{DPPH} \bullet-$ methanol solution $(0.1 \mathrm{mM})$. Scavenging capacity was read spectrophotometrically by monitoring the decrease in absorbance at $517 \mathrm{~nm}$. Percent radical scavenging activity or percentage of inhibition was determined using the following equation where I represents the inhibition of $\mathrm{DPPH} \bullet$, in percentage, and A the absorbance at $517 \mathrm{~nm}$ of the blank and sample.

$$
\mathrm{I}(\%)=\frac{\mathrm{A}_{\text {blank }}-\mathrm{A}_{\text {sample }}}{\mathrm{A}_{\text {blank }}} \times 100
$$

The ABTS or TEAC (Trolox Equivalent Antioxidant capacity) was determined according to Re et al. (1999). This method is based on the ability of an antioxidant to scavenge the preformed radical cation ABTS+ relative to that of the standard antioxidant Trolox. ABTS $(7 \mathrm{mM})$ was made to react with potassium persulfate $(2.45$ $\mathrm{mM}$ ) during 16 hours at room temperature, so as to obtain the ABTS+ radical. Then, the solution was diluted in phosphate buffer $(\mathrm{pH} 7)$ to an absorbance of $0.700 \pm 0.020$ at $734 \mathrm{~nm} .90 \mu \mathrm{L}$ of the sample or control were then added to $2910 \mu \mathrm{L}$ of the ABTS + in phosphate buffer solution and absorbance at $734 \mathrm{~nm}$ was then read at 1, 2, 3 and $6 \mathrm{~min}$ of reaction. In controls, deionized water was used. TEAC values were expressed in $\mu \mathrm{mol}$ Trolox/g of sample. All reagents used in AO determinations, DPPH, ABTS (purity $\geq 98 \%$ ) and Trolox (purity $\geq 97 \%$ ), were purchased from Sigma-Aldrich.

\subsection{Thermal treatments.}


The products having higher antioxidant capacity underwent thermal treatment in order to evaluate the effect of thermal processing of the food on AO capacity. Solutions of the sugars were prepared and treated at 60,80 and $100{ }^{\circ} \mathrm{C}$ during 10, 30 and $60 \mathrm{~min}$ in a thermostatic bath (P.Selecta, Precisdig). After that, AO properties were evaluated by the DPPH• and TEAC methods.

\subsection{Statistical analysis}

All analytical determinations were performed at least in triplicate. Results were statistically analyzed using Statgraphics Centurion XVI.

\section{RESULTS}

\subsection{Physicochemical characteristics of sugarcane products}

Physicochemical attributes of white and non-refined sugarcane sugars are given in table 1. Although water activity was relatively similar for all samples, water content was significantly higher for cane honey than for jaggeries and crystal sugars. Jaggeries water content was in the range of the reported by other authors (Mujica et al., 2008). TSS content was close to 1 for all sugars except for $\mathrm{CH}$, which lower TSS content suggests a significant amount of other compounds different from sugars. Crystal sugars have higher $\mathrm{pH}$ than jaggeries and cane honey. Carbonatation takes place in the sugar manufacturing process which facilitates the precipitation of undesired impurities and increases the $\mathrm{pH}$ of the syrup. Other compounds such as organic acids and the presence of citric acid as a preservative in the case of $\mathrm{CH}$, can also be responsible for a difference in $\mathrm{pH}$.

Concerning colour, a correlation between the purity and the IU. is observed. As expected, white sugar presented very low IU., whereas crystallized brown sugar had higher indexes. Brown sugar containing molasses had a colour similar to jaggeries and cane honey had the highest IU. The values obtained in the present work for brown sugars $(\mathrm{CB}, \mathrm{DB}, \mathrm{LB}$ and $\mathrm{RB})$ were in the range of the reported by Wojtczak et al. (2013) who analyzed brown and raw cane sugars. Other authors (Saska et al, 2010) have reported values for sugarcane juice between 10,000 and 20,000 IU. and higher than 38,000 for molasses (Saska \& Chou, 2002).

Three were the sugars identified by ion exchange chromatography: sucrose, glucose and fructose. In white sugar, only sucrose was identified and reducing sugars were not detected, whereas a rather negligible amount of glucose and fructose was identified in 
coated and dark brown sugars. Other brown sugars had less sucrose, its presence being even lower for jaggeries and, particularly, for cane honey. Although fructose and glucose are present in the raw material, reducing sugars may also come from sucrose inversion during post-harvesting and processing.

\subsection{Total phenolic content.}

According to Slinkard \& Singleton (1977) and Singleton et al. (1999) reducing sugars may react with the Folin-Ciocalteau reagent apparently increasing the total phenol content of the samples. In order to eliminate this interference, sucrose, fructose and glucose standards were added to standard gallic acid curves. Results confirmed that there was an interference of the three sugars, and that this interference was more significant when reducing sugars were added

Apparent and corrected phenol contents of the non-refined cane sugars are shown in table 2. Phenols were not found in white sugar, whereas all non-refined alternatives presented certain phenolic content. Cane honey, regular jaggery and light jaggery have the highest phenol content, closely followed by granulated jaggery; whereas phenolic content in brown sugars is significantly lower. Harish-Nayaka et al. (2009) reported a similar phenolic content in brown sugar (0.37), whereas Payet et al. reported a wider interval (0.1-0.41). In the case of jaggery, Harish-Nayaka et al. (2009) obtained a higher value (3.83). Differences in processing, as well as in the origin and sugarcane cultivar could be responsible for these discrepancies (Kadam et al., 2008). In addition, most of the values available in the literature do not consider the interference of sugars in the analysis for which some data might be slightly overestimated. Nevertheless, the presence of sugars in the samples had only a significant impact on the results in the case of sugarcane honey, which contains around $65 \%$ of inverted sugar, moderately modifies the real value in light and regular jaggeries (15-20\% of inverted sugars), and has very small impact in the rest of cases, it being totally negligible in brown sugars which inverted sugar content is below $3 \%$.

\subsection{Total flavonoid content.}

In table 2, total flavonoids in the sugarcane products are given in $\mathrm{mg}$ of Quercetin Equivalents (QE) per gram of product and per gram of sugar. Flavonoids were present in all the non-refined sugarcane products analyzed, these being significantly abundant in sugarcane honey, as well as in jaggeries, especially light and regular jaggery blocks. 
The presence of sugars may also have interfered in this analysis, as some flavonoid content was obtained for white sugar; however, taking into account the previous assay, it was considered that this influence could only have significantly affected the cane honey value. Comparison with similar values reported by other authors was not possible since similar data were not found in the literature.

The aluminium chloride colorimetric method using quercetin as a standard has been widely used to determine the total flavonoid content (Dowd, 1959; Chang et al., 2002; Luximon-Ramma et al., 2002; Kumazawa et al., 2004; Bahorun et al., 2004; Lin \& Tang, 2007); however, the generalized use of this method to determine total flavonoid content has been recently questioned (Denni \& Mammen, 2012). According to these authors, different flavonoids have picks of absorbance at different wave lengths and, when reacted with $\mathrm{AlCl}_{3}$ flavonols have absorption maxima around $440 \mathrm{~nm}$, whereas most flavones exhibit their maxima below $400 \mathrm{~nm}$. In our particular case, it was noticed that values for total flavonoids were higher than values for total phenols. Since quercetin exhibits absorption maxima at $445 \mathrm{~nm}$, whereas some of the flavones abundant in sugarcane (tricin and apigenin) have absorption maxima below $400 \mathrm{~nm}$ when reacted with $\mathrm{AlCl}_{3}$, measuring the absorbance of the reaction at $368 \mathrm{~nm}$ using quercetin as a standard may overestimate the total flavonoid content. On the contrary measuring the absorbance above $400 \mathrm{~nm}$, as it has also been suggested, may underestimate the flavonoid content. However, this colorimetric method is commonly used in the literature to estimate the total flavonoid content without taking these considerations into account. The present results indicate that, as an average, jaggeries have 5 times more flavonoids than coated brown sugar.

\subsection{Antioxidant properties of sugarcane products.}

In Figure 1 the evolution of DPPH• inhibition during two hours of reaction is shown for the twelve products studied at one concentration $(1: 5 \mathrm{w} / \mathrm{v})$, and at different concentrations for a single product $(\mathrm{RJ})$. In all cases, kinetics of the DPPH $\bullet$ reaction corresponded to a hyperbolic curve, which is characteristic of components that react slowly with DPPH• (Brand-Williams, 1995). In fact, for some products, the steady state value was not reached in the two hours registered at the highest concentrations assayed. According to these results, the components present in the sugarcane derived products have a slow-kinetics response to the DPPH• assay; nevertheless, a combination of fast + slow response was also identified in jaggeries and cane honey. According to Sendra et 
al. (2006), the antioxidants that are capable of both fast and slow hydrogen atom transfer are components which normally have a free or mono-substituted catechol group; whereas the slow-kinetics group would consist of components having exclusively slow-acting antiradical groups, such as those which lack the catechol group in the B-ring. Considering the phenolic compounds identified by other authors in sugarcane juice and sugarcane derivatives (Duarte-Almeida et al., 2006; Harish-Nayaka et al., 2009) components such as luteolin and some phenolic acids would contribute to the fast + slow response, whereas tricin and apigenin (most abundant flavones in sugarcane) would be responsible for the slow response observed in the non-refined sugars.

Significant differences were found between white sugar and the non-refined ones, indicating that all the non-refined alternatives analyzed exhibit in vitro antiradical activity (Fig. 1a). Among non-refined sugars, brown sugars together with wet brown sugar and sugar with molasses presented the lowest antiradical activity, raw brown sugar and molassed sugar being classified in a different group with slightly higher antiradical activity. On the opposite side, jaggeries and cane honey presented the highest capacity to inhibit DPPH• radical, cane honey showing the highest percentage of inhibition and dark jaggery the lowest. However, it must be taken into account that cane honey contains citric acid as a preservative, which could have affected the DPPH• scavenging measurement (Dawidowicz et al., 2012). Results evidence that degree of refining or the process undergone highly determines the amount of antioxidant components present in the sugarcane products. It also may be observed that although all the non-refined alternatives to white sugar have certain antiradical activity, jaggeries and cane honey have, as an average, six times more antiradical activity than brown sugars.

For those products which showed the highest antiradical activity $(\mathrm{CH}, \mathrm{RJ}, \mathrm{LJ}$ and GJ), the concentration providing $50 \%$ inhibition $\left(\mathrm{IC}_{50}\right)$ was calculated by plotting the sample concentration (final concentration in cuvette) against the corresponding scavenging effect. Results indicated that cane honey has an $\mathrm{IC}_{50}$ equal to $1.31 \mathrm{~g}_{\text {product }} / \mathrm{mL}(0.92$ $\left.\mathrm{g}_{\text {sugar }} / \mathrm{mL}\right), \mathrm{RJ}$ and $\mathrm{LJ}$ have an $\mathrm{IC}_{50}$ of $2.00 \mathrm{~g}_{\text {product }} / \mathrm{mL}\left(1.45\right.$ and $1.57 \mathrm{~g}_{\text {sugar }} / \mathrm{mL}$, respectively), and granulated jaggery $2.5 \mathrm{~g}_{\text {product }} / \mathrm{mL}\left(2.02 \mathrm{~g}_{\text {sugar }} / \mathrm{mL}\right)$.

It is recommended the use of more than one single method to estimate the antioxidant activity of complex samples (Ozgen et al., 2006). In this case, the ABTS free radical method, which has been reported to be more sensitive to hydrophilic antiradicals (Del 
Caro et al., 2004), was used in addition to DPPH• radical scavenging capacity. TEAC values were obtained by the ABTS method at 1, 3 and 6 min of reaction (Fig. 2). Reaction continued for the 6 minutes analyzed in all cases, although differences were more significant in samples that showed higher AO capacity. TEAC values at 6 min of reaction were taken as definitive. Except for the white sugar, which showed a negligible AO activity, all the non-refined sugars exhibited certain capacity to scavenge the ABTS + free radical. In general, results were similar to the obtained with the DPPH• analysis, since brown sugars presented the lowest AO capacity and light jaggeries and cane honey had the highest ones. However, these two groups were more differentiated than before, dark jaggery belonging to the same group than all brown sugars, and granulated jaggery being closer to the other light jaggeries and cane honey. Differences between the DPPH • and TEAC-ABTS methods were probably due to their different sensitivity to the antiradical compounds that may be present in the sugarcane products. Time of reactions could also have produced some differences; nevertheless, ABTS reaction is usually faster than DPPH• inhibition reaction (Ozgen et al., 2006).

Although values reported in the literature are not easily comparable since, apart from the method used, extract type, sample concentration or reaction times originate differences in the results, it is interesting to compare the AO capacity of sugarcane products with the AO properties of other foods. TEAC values obtained for jaggeries and cane honey were in the range of fruits with a considerable AO capacity such as blackberry, raspberry, strawberry, pineapple or orange $(9-21 \mu \mathrm{mol} \mathrm{TE} / \mathrm{g}$ as reported by Ozgen et al., 2006 and Pellegrini et al., 2003), significantly higher to other fruits such as apple, banana, mango, apricot, pear or plum (1.3-5 $\mu \mathrm{mol} \mathrm{TE} / \mathrm{g}$ as reported by Pellegrini et al., 2003 and Vijaya et al., 2010) and also higher to vegetables such as onion, broccoli, tomato, carrot, pepper or spinach $(0.4-8 \mu \mathrm{mol} \mathrm{TE} / \mathrm{g}$ as reported by Baourun et al., 2004 and Pellegrini et al., 2003). Brown sugars and dark jaggery also presented values in the range of fruits such as apple, orange or mango and higher to most vegetables. However, it is important to point out that sugarcane products are the result of sugarcane juice concentration and have very small amounts of water, whereas values provided for fruits and vegetables are usually expressed per gram of fresh weight.

In any case, in order to estimate the real contribution of a food to the AO intake through the diet, the frequency of consumption must be considered. Direct intake of sugar in Spain, i.e. direct consumption of sugar at home, is around $340 \mathrm{~g} / \mathrm{month}$. Taking into 
account this value, replacement of white refined sugar for a non-refined alternative would have an impact on the diet from 1.4 to $9.1 \mathrm{mmol} \mathrm{TE} / \mathrm{month}$, depending on the non-refined sugar used as a substitutive. This is of considerable importance since, for example, the TE intake due to apple consumption is $4.9 \mathrm{mmol} \mathrm{TE} / \mathrm{month}$ (assuming Spanish consumption per capita) and that the TE intake due to fruits known for having a high AO capacity such as blackberry is almost negligible for being rarely consumed (assuming Spanish consumption per capita). If going further and considering nonrefined sugarcane products as functional ingredients for the food industry, replacing refined sugar in some sugar-rich products may substantially increase this AO intake.

\subsection{Correlation between phenolic and flavonoid content and free radical scavenging assays.}

The correlation coefficients (Pearson's) between the total phenolic content (apparent and corrected) measured by the Folin-Ciocalteu assay, the flavonoid content measured by the aluminum chloride colorimetric method, and the antioxidant properties of the samples as indicated by the DPPH and ABTS methods were calculated. All the combinations calculated were significantly correlated ( 0.01 significance level), which would indicate that the antioxidant properties of the sugarcane derived products are due to their phenolic content. Although all correlation coefficients were significant, certain differences were observed when comparing total apparent or corrected phenol content. Flavonoid content and DPPH assay correlated better with total apparent content $(0.942$ and 0.996, respectively) which could indicate that both flavonoid and DPPH methods are also influenced by the reducing sugars present in the samples; on the contrary, ABTS correlation coefficient was higher when the corrected values were used (0.990), which could suggest sugars are not significantly interfering in this assay.

In sugar-derived samples Maillard reaction compounds, which are involved in the colour and flavour of the sugar products, may also exhibit antioxidant activity (Payet et al., 2005, Dittrich et al., 2003). Considering that these products also react with the Folin-Cicolteau reagent (Harish-Nayaka et al., 2009), other authors have attributed low correlation coefficients between total phenol content and AO activity to Maillard reaction products (Payet et al., 2005). In the present work, however, AO activity and phenolic content do correlate significantly.

\subsection{Effect of thermal treatment on the AO capacity of sugarcane products.}


The results corresponding to the AO activity of sugar samples after thermal treatments is summarized in table 3 . The effect of thermal treatment was heterogeneous and results were dependent not only on the particular sugarcane product being analyzed, but also on the assay method used. Depending on the combination of time and temperature used, antioxidant activity of samples decreased, did not change or even increased. In line with this, cooking and other thermal treatments have been reported to increase the $\mathrm{AO}$ capacity of some vegetables or, in other cases, decrease it (Yamaguchi et al., 2001). According to the results obtained, short times and low to medium temperatures would be promoting the destruction of antioxidants naturally present in the samples, whereas an intensification of the treatment would originate the creation of other compounds or more active ones. In the case of sugarcane products, Maillard reactions products could have appeared and, therefore, produced an increase in the AO capacity. An increase in antioxidants bioavailability or an improved activity of naturally occurring antioxidants may also occur due to treatments involving heating (Chan et al., 2009; Yamaguchi et al., 2001). On the other hand, differences due to the assay method used could be explained by their different sensitivity to the different antioxidant compounds present in the sample.

Although statistically significant differences were observed for some products such as brown sugar and cane honey, the thermal treatment did not produce a severe change in the AO capacity. AO properties of jaggeries were particularly not affected. As said, food processing can improve the properties of naturally occurring antioxidants or induce the formation of new compounds with antioxidant capacity, so that the overall antioxidant activity may increase or remain unchanged (Chan et al., 2009). Therefore, in the particular case of non-refined sugarcane products, it may be deduced that processing involving temperatures lower than $100{ }^{\circ} \mathrm{C}$ and times shorter than $60 \mathrm{~min}$, would not significantly affect their antioxidant activity.

\section{CONCLUSIONS}

Results of the present work confirm that the non-refined sugarcane products studied exhibit in vitro antioxidant activity and that degree of refining determines the phenolic content and AO capacity of the products. Therefore, these sugarcane derivatives, which are available in supermarkets for direct consumption, are a promising source of natural antioxidants. Contribution of $\mathrm{AO}$ to the diet as a result of replacing white refined sugar for these alternatives has been discussed, and results indicate that the potential AO 
intake due to the sugarcane products can be considerable, especially if jaggeries or cane honey are used as a substitute. Full replacement of white sugar for the non refined alternatives may not be realistic since, among other reasons, significant changes in the food characteristics such as colour or flavour may be expected. In relation to this, and according to the physicochemical characteristics of the products studied, changes expected in the formulated product would be indirectly related to the AO properties of the sugar. In any case, acceptance by a consumer panel should finally confirm or reject the new formulated products which, on the other hand, would have the added value of providing health benefits. Taking into account that sugar and sugar-rich products are widely consumed all over the world, the results of the present work should encourage the use of non-refined sugars in reformulation of traditional foods or in the design of new sugar-rich products with increased nutritional properties.

\section{ACKNOWLEDGEMENTS}

Authors would like to acknowledge the Universitat Politècnica de València (Project PAID2010-2420) and Generalitat Valenciana Government (GV/2013/047) for financial support.

\section{REFERENCES}

Abbas, S.R., Sabir, W.M., Ahmad, S.D., Boligon A.A. and Athayde, M.L. (2014). Phenolic profile, antioxidant potential and DNA damage protecting activity of sugarcane (Saccharum officinarum). Food Chemistry, 147, 10-16.

Amer, S., Naa K.J., El-Abasya, M., Motobua, M., Koyamaa, Y., Kogee, K. and Hirotaa, Y. (2004). Immunostimulating effects of sugar cane extract on X-ray radiation induced immunosuppression in the chicken. International Immunopharmacology 4, $71-77$.

Bahorun, T., Luximon-Ramma, A., Crozier, A. and Aruoma, O.I. (2004). Total phenol, flavonoid, proanthocyanidin and vitamin $\mathrm{C}$ levels and antioxidant activities of Mauritian vegetables. Journal of the Science of Food and Agriculture, 84, 1553-1561.

Brand-Williams, W., Cuvelier, M.E. and Berset, C. (1995). Use of a free radical method to evaluate antioxidant activity. Lebensmittel-Wissenschaft und -Technologie, 28, 2530.

Cataldi, T.R.I., Margiotta, G., Iasi, L., Di Chio, B., Xiloyannis, C. and Bufo, S.A. (2000). Determination of Sugar Compounds in Olive Plant Extracts by Anion- 
Exchange Chromatography with Pulsed Amperometric Detection. Analytical Chemistry, 72 (16), 3902-3907.

Chan, E.W.C., Lin, Y.Y., Wong, S.K., Lim, K.K., Tan, S.P., Lianto, F.S., Yong, M.Y. (2009). Effects of different drying methods on the antioxidant properties of leaves and tea of ginger species. Food Chemistry, 113, 166-172.

Chang, C.C., Yang, M.H., Wen, H.M. and Chern, J.C. (2002). Estimation of Total Flavonoid Content in Propolis by Two Complementary Colorimetric Methods. Journal of Food and Drug Analysis, 10(3), 178-182.

Dawidowicz, A.L., Wianowska, D. and Olszowy, M. (2012). On practical problems in estimation of antioxidant activity of compounds by $\mathrm{DPPH} \cdot$ method (Probems in estimation of antoxidant activity). Food Chemistry, 131 (3), 1037-1043.

De Whalley, H.C.S. (1964) ICUMSA Methods of Sugar Analysis p. 57. Elsevier Publishing Co., Amsterdam.

Del Caro, A., Piga, A., Vacca, V. and Agabbio, M. (2004). Changes of flavonoids, vitamin $\mathrm{C}$ and antioxidant capacity in minimally processed citrus segments and juices during storage. Food Chemistry 84, 99-105.

Denni, M. and Mammen, D. (2013). A critical evaluation on the reliability of two aluminum chloride chelation methods for quantification of flavonoids. Food Chemistry 135, 1365-1368.

Dittrich, R., El-Massry, F., Kunz, K., Rinaldi, F., Peich, C. C., Beckmann, M. W. and Pischetsrieder, M. (2003). Maillard reaction products inhibit oxidation of human lowdensity lipoproteins in vitro. Journal of Agricultural Food Chemistry, 51, 3900-3904.

Dowd, L.E. (1959). Spectrophotometric Determination of chercetin. Analytical chemistry, 31(7), 1184-1187.

Duarte-Almeida, J.M., Negri, G., Salatina, A., de Carvalho, J.E. and Lajolo, F.M. (2007). Antiproliferative and antioxidant activities of a tricin acylated glycoside from sugarcane (Saccharum officinarum) juice. Phytochemistry, 68 (2007) 1165-1171.

Duarte-Almeida, J.M., Vidal Novoa, A., Fallarero Linares, A., Lajolo, F.J. and Genovese, M.I. (2006). Antioxidant Activity of Phenolics Compounds From Sugar Cane (Saccharum officinarum L.) Juice. Plant Foods for Human Nutrition 61, 187192.

El-Abasy, M., Motobu, M., Na., K.J., Shimura, K., Nakamura, K., Koge, K., Onodera, T. and Hirota, Y. (2003). Protective effects of sugar cane extracts (SCE) on Eimeria tenella infection in chickens. Journal of Veterinary Medicine Sci. 65(8), 865-871. 
El-Abasy, M., Motobu, M., Nakamura, K., Koge, K., Onodera, T., Vainio, O., Toivanen, P. and Hirota, Y. (2004). Preventive and therapeutic effects of sugar cane extract on cyclophosphamide-induced immunosuppression in chickens. International Immunopharmacology 4 (2004) 983-990.

Feng, S., Luo, Z., Zhang, Y., Zhong, Z. and Lu, B. (2014). Phytochemical contents and antioxidant capacities of different parts of two sugarcane (Saccharum officinarum L.) cultivars. Food Chemistry, 161, 452-458.

Galloway, J.H. 2000. Sugar. In: The Cambridge World History of Food, Cambridge: Cambridge University Press.

Guimaraes, C.M., Giao, M.S., Martínez, S.S., Pintado, A.I., Pintado, M.E., Bento, L.S. and Malcata, S. (2007). Antioxidant Activity of Sugar Molasses, Including Protective Effect Against DNA Oxidative Damage. Journal of Food Science (Food Chemistry and Toxicology), 72(1), 39-43.

Harish Nayaka, M.A., Sathisha, U.V., Manohara, M.P., Chandrashekara, K.B. and Dharmesh, S.M. (2009) Cytoprotective and antioxidant activity studies of jaggery sugar. Food Chemistry 11, 113-118.

Jenkins, G.N. (1970). Enamel protective factors in food. Journal of Dental Research, 49, 1318.

Kadam, U.S., Ghosh, S.B., Strayo De. and Suprasanna, P. (2008). Antioxidant activity in sugarcane juice and its protective role against radiation induced DNA damage. Food Chemistry 106, 1154-1160.

Koge, K., Yukie, N., Takeo, M., Mamoru, S. and Seiichi, A. (2001). Inhibitory Effects of Sugar Cane Extracts on Liver Injuries in Mice. Journal of the Japanese Society for Food Science and Technology, 48 (4), 231-137.

Kumazawa, S., Hamasaka, T. and Nakayama, T. (2004). Antioxidant activity of propolis of various geographic origins. Food Chemistry, 84, 329-339.

Lin, J.Y. and Tang, C.Y. (2007). Determination of total phenolic and flavonoid contents in selected fruits and vegetables, as well as their stimulatory effects on mouse splenocyte proliferation. Food Chemistry 101,140-147.

Lo, D.Y., Chen, T.H., Chien, M.S., Koge, K., Hosono, A., Kaminogawa, S. and Lee, W.C. (2005). Effects of Sugar Cane Extract on the modulation of immunity in pigs. Journal of Veterinary Medicine Sci. 67(6). 591-597. 
Luximon-Ramma, A., Bahorun, T., Soobrattee, M.A. and Aruoma, O.I. (2002). Antioxidant Activities of Phenolic, Proanthocyanidin, and Flavonoid Components in Extracts of Cassia fistula. Journal of Agricultural and Food Chemistry, 50, 5042-5047.

Motobu, M., Amer, A., Koyama, Y., Hikosaka, K., Sameshima, T., Yamada, M., Nakamura, K., Koge, K., Kang, C.B., Hayasidani, H. and Hirota Y. (2006). Protective Effects of Sugar Cane Extract on Endotoxic Shock in Mice. Phytotherapy research, 20, $359-363$.

Mujica, M.V., Guerra, M., and Soto, N. (2008). Effect of cane variety, washing and endpoint temperature on the quality of granulated "panela" sugarcane. Efecto de la variedad, lavado de la caña y temperatura de punteo sobre la calidad de la panela granulada. Interciencia, 33(8), 598-603.

Noa, M., Mendoza, S., Mas, R. and Mendoza, N. (2002) Effect of D-003, a mixture of high molecular weight primary acids from sugar cane wax, on CL4C-induced liver acute injury in rats. Drugs Exp Clin Res 28(5): 177-183.

Ozgen, M., Reese, R.N., Tulio, A.Z., Scheerens, J.C. and Miller, R. (2006). Modified 2,2-Azino-bis-3-ethylbenzothiazoline-6-sulfonic Acid (ABTS) Method to Measure Antioxidant Capacity of Selected Small Fruits and Comparison to Ferric Reducing Antioxidant Power (FRAP) and 2,2'-Diphenyl-1-picrylhydrazyl (DPPH) Methods. Journal of Agricultural and Food Chemistry, 54, 1151-1157.

Payet, B., Chong Sing, A.S. and Smadja, J. (2005). Assessment of antioxidant activity of cane browns sugars by ABTS and DPPH radical scavenging assays: determination of their polyphenolic and volatile constituents. Journal of Agricultural and Food Chemistry, 53, 10074-10079.

Pellegrini, N., Serafini, M., Colombi, B., Del Rio, D., Salvatore, S., Bianchi, M. and Brighenti, F. (2003). Total Antioxidant Capacity of Plant Foods, Beverages and Oils Consumed in Italy Assessed by Three Different In Vitro Assays. The Journal of Nutrition (The American Society for Nutritional Sciences), 133(9), 2812-2819.

Phillips, K.M., Carlsen, M. and Blomhoff, R. (2009). Total Antioxidant Content of Alternatives to Refined Sugar. Journal of the American Diet Association, 109:64-71.

Re, R., Pellegrini, N., Proteggente, A., Pannala, A., Yang, M. and Rice-Evans, C. (1999). Antioxidant activity applying an improved ABTS radical cation decolorization assay. Free radical biology and medicine, 26 (9/10), 1231-1237. 
Saska, M. and Chou, C.C. (2002). Antioxidant Properties of Sugarcane Extracts. Proceedings of the First Biennial World Conference on Recent Development in Sugar Technologies. May 16-17, 2002 Florida, USA.

Saska, M., Zossi, B.S. and Liu, H. (2010). Removal of colour in sugar cane juice clarification by defecation, sulfitation and carbonation.International Sugar Journal, 112, 258-264.

Sendra, J.M., Sentandreu, E. and Navarro, J.L. (2006). Reduction kinetics of the free stable radical 2,2-diphenyl-1-picrylhydrazyl (DPPH•) for determination of the antiradical activity of citrus juices. European Food Research and Technology, 223, 615-624.

Singleton, V., Orthofer, R. and Lamuela-Raventós, R.M. (1999). Analysis of total phenols and other oxidation substrates and antioxidants by means of folin-ciocalteu reagent. Methods in enzymology, 299, 152-178.

Slinkard, K. and Singleton, V. L. (1977). Total phenol analysis: automation and comparison with manual methods. American Journal of Enology and Viticulture, 28 (1), 49-55.

Varzakas, T., and Chryssanthopoulos, C. (2012). Chapter 11. Nutritional and health aspects of sweeteners. In: Varzakas, T., Labropoulos, A., and Anestis, S. Sweeteners: nutritional aspects, applications and production technology. pp. 329-366, CRC Press, Taylor and Francis Group.

Vijaya Kumar Reddy, C., Sreeramulu, D. and Raghunath, M. (2010). Antioxidant activity of fresh and dry fruits commonly consumed in India. Food Research International, 43, 285-288.

Wojtczak, M., Antczak, A. and Lisik, K. (2013). Contamination of commercial cane sugars by some organic acids and some inorganic anions. Food Chemistry 136, 193198.

Wolfe, K., Wu, X. and Liu, R.H. (2003). Antioxidant activity of Apple peels. Journal of agricultural and food chemistry, 51, 609-614.

Yamaguchi, T., Mizobuchi, T., Kajikawa, R., Kawashima, H., Miyabe, F., Terao, J., Takamura, H., Matoba, T. (2001). Radical-scavenging activity of vegetables and the effect of cooking on their activity. Food Science and Technology Research, 7(3), 250257.

Yamauchi, K., Buwjoom, T., Koge, K. and Ebashi, T. (2006) Histological Intestinal Recovery in Chickens Refed Dietary Sugar Cane Extract. Poultry Science 85, 645-65. 
Yao, L.H., Jiang, Y.M., Shi, J., Toma's-Berbera'n, F.A., Datta, N., Singanusong, R. and Chen, S.S. (2004). Flavonoids in food and their health benefits. Plant Foods for Human Nutrition, 59: 113-122. 
Table 1. Physicochemical characteristics of sugarcane products. Means \pm standard deviations from triplicates.

\begin{tabular}{|c|c|c|c|c|c|c|c|c|}
\hline & $\begin{array}{c}\text { Water content } \\
(\%)\end{array}$ & $\begin{array}{c}\text { Water activity } \\
\left(a_{w}\right)\end{array}$ & $\begin{array}{l}\text { TSS } \\
\left(\mathrm{x}_{\mathrm{s}}\right) \\
\end{array}$ & $\mathrm{pH}(1: 4)$ & $\begin{array}{l}\text { ICUMSA COLOUR } \\
\text { (IU. 420) }\end{array}$ & $\begin{array}{l}\text { Glucose } \\
\left(\mathrm{g} / \mathrm{g}_{\text {product }}\right)\end{array}$ & $\begin{array}{l}\text { Fructose } \\
\left(\mathrm{g} / \mathrm{g}_{\text {product }}\right)\end{array}$ & $\begin{array}{l}\text { Sucrose } \\
\left(\mathrm{g} / \mathrm{g}_{\text {product }}\right)\end{array}$ \\
\hline $\mathrm{W}$ & $1.3 \pm 0.1^{\mathrm{a}}$ & $0.68 \pm 0.07^{\mathrm{e}}$ & $1.00 \pm 0.05^{\mathrm{e}}$ & $6.3 \pm 0.2^{\mathrm{h}}$ & $31 \pm 33^{\mathrm{a}}$ & nd & nd & $0.97 \pm 0.09^{\mathrm{f}}$ \\
\hline $\mathrm{CB}$ & $1.6 \pm 0.3^{\mathrm{a}}$ & $0.63 \pm 0.011^{\mathrm{b}, \mathrm{c}, \mathrm{d}, \mathrm{e}}$ & $1.00 \pm 0.05^{\mathrm{e}}$ & $6.34 \pm 0.02^{\mathrm{h}}$ & $2,740 \pm 41^{\mathrm{b}}$ & $0.09 \pm 0.0009^{\mathrm{a}}$ & $0.001 \pm 0.0011^{\mathrm{a}}$ & $0.94 \pm 0.08^{f}$ \\
\hline DB & $1.2 \pm 0.1^{\mathrm{a}}$ & $0.62 \pm 0.05^{\mathrm{a}, \mathrm{b}, \mathrm{c}, \mathrm{d}}$ & $1.00 \pm 0.06^{\mathrm{d}, \mathrm{e}}$ & $5.72 \pm 0.09^{\mathrm{e}, \mathrm{f}}$ & $4,783 \pm 384^{c}$ & $0.0004 \pm 0.0008^{\mathrm{a}}$ & $0.000 \pm 0.0000^{\mathrm{a}}$ & $0.9 \pm 0.2^{\mathrm{e}, \mathrm{f}}$ \\
\hline LB & $1.2 \pm 0.1^{\mathrm{a}}$ & $0.61 \pm 0.04^{\mathrm{a}, \mathrm{b}, \mathrm{c}}$ & $0.99 \pm 0.08^{\mathrm{c}, \mathrm{d}, \mathrm{e}}$ & $6.25 \pm 0.12^{\mathrm{g}, \mathrm{h}}$ & $3,692 \pm 172^{\mathrm{b}, \mathrm{c}}$ & $0.002 \pm 0.0012^{\mathrm{a}}$ & $0.0016 \pm 0.0008^{\mathrm{a}}$ & $0.882 \pm 0.006^{\mathrm{d}, \mathrm{e}, \mathrm{f}}$ \\
\hline $\mathrm{RB}$ & $1.4 \pm 0.1^{\mathrm{a}}$ & $0.59 \pm 0.02^{\mathrm{a}, \mathrm{b}}$ & $1.0 \pm 0.06^{\mathrm{d}, \mathrm{e}}$ & $6.1 \pm 0.2^{\mathrm{g}}$ & $4,598 \pm 138^{c}$ & $0.0010 \pm 0.0005^{\mathrm{a}}$ & $0.0015 \pm 0.0002^{\mathrm{a}}$ & $0.86 \pm 0.09^{\mathrm{d}, \mathrm{e}, \mathrm{f}}$ \\
\hline WB & $1.2 \pm 0.2^{\mathrm{a}}$ & $0.57 \pm 0.02^{\mathrm{a}}$ & $1.0 \pm 0.06^{\mathrm{d}, \mathrm{e}}$ & $5.21 \pm 0.14^{b}$ & $9,504 \pm 578^{\mathrm{d}}$ & $0.010 \pm 0.005^{\mathrm{a}, \mathrm{b}}$ & $0.01 \pm 0.011^{\mathrm{a}}$ & $0.9 \pm 0.10^{\mathrm{d}, \mathrm{e}, \mathrm{f}}$ \\
\hline MB & $1.3 \pm 0.2^{\mathrm{a}}$ & $0.572 \pm 0.008^{\mathrm{a}}$ & $1.0 \pm 0.12^{\mathrm{c}, \mathrm{d}, \mathrm{e}}$ & $5.6 \pm 0.12^{\mathrm{d}, \mathrm{e}}$ & $17,002 \pm 156^{\mathrm{h}}$ & $0.008 \pm 0.005^{\mathrm{a}, \mathrm{b}}$ & $0.006 \pm 0.002^{\mathrm{a}}$ & $0.83 \pm 0.06^{\mathrm{c}, \mathrm{d}, \mathrm{e}, \mathrm{f}}$ \\
\hline GJ & $3.6 \pm 0.1^{b}$ & $0.608 \pm 0.003^{\mathrm{a}, \mathrm{b}, \mathrm{c}}$ & $1.0 \pm 0.13^{\mathrm{c}, \mathrm{d}}$ & $5.26 \pm 0.02^{\mathrm{b}}$ & $16,606 \pm 306^{\mathrm{g}, \mathrm{h}}$ & $0.030 \pm 0.010^{\mathrm{b}}$ & $0.021 \pm 0.002^{\mathrm{a}}$ & $0.75 \pm 0.06^{\mathrm{a}}$ \\
\hline LJ & $4.5 \pm 0.3^{c}$ & $0.62 \pm 0.02^{\mathrm{a}, \mathrm{b}, \mathrm{c}, \mathrm{d}}$ & $0.94 \pm 0.16^{\mathrm{b}}$ & $5.460 \pm 0.013^{\mathrm{c}, \mathrm{d}}$ & $15,142 \pm 1,421^{\mathrm{f}}$ & $0.1 \pm 0.13^{\mathrm{c}}$ & $0.053 \pm 0.007^{\mathrm{b}}$ & $0.7 \pm 0.10^{\mathrm{b}}$ \\
\hline RJ & $7.0 \pm 0.7^{\mathrm{d}}$ & $0.67 \pm 0.010^{\mathrm{d}, \mathrm{e}}$ & $0.9 \pm 0.2^{\mathrm{b}}$ & $5.35 \pm 0.03^{b, c}$ & $15,546 \pm 1,270^{\mathrm{f}, \mathrm{g}}$ & $0.08 \pm 0.02^{\mathrm{d}}$ & $0.07 \pm 0.010^{\mathrm{b}}$ & $0.6 \pm 0.12^{\mathrm{b}}$ \\
\hline DJ & $3.1 \pm 0.5^{\mathrm{b}}$ & $0.60 \pm 0.03^{\mathrm{a}, \mathrm{b}, \mathrm{c}}$ & $1.0 \pm 0.3^{\mathrm{c}}$ & $5.9 \pm 0.02^{\mathrm{f}}$ & $11,552 \pm 1,543^{\mathrm{e}}$ & $0.019 \pm 0.002^{\mathrm{a}, \mathrm{b}}$ & $0.019 \pm 0.006^{\mathrm{a}}$ & $0.80 \pm 0.05^{\mathrm{c}, \mathrm{d}, \mathrm{e}}$ \\
\hline $\mathrm{CH}$ & $25.9 \pm 0.6^{\mathrm{e}}$ & $0.656 \pm 0.003^{\mathrm{c}, \mathrm{d}, \mathrm{e}}$ & $0.8 \pm 0.3^{\mathrm{a}}$ & $4.55 \pm 0.04^{\mathrm{a}}$ & $18,715 \pm 201^{\mathrm{i}}$ & $0.23 \pm 0.03^{\mathrm{e}}$ & $0.23 \pm 0.06^{\mathrm{c}}$ & $0.25 \pm 0.06^{\mathrm{c}}$ \\
\hline
\end{tabular}

a,b,c...Values with different superscript letters within the same column are significantly different $(\mathrm{p}<0.05)$.

W, white sugar; CB, coated brown sugar; LB, light brown sugar; RB, raw brown sugar; DB, dark brown sugar; WB, wet brown sugar; MB, raw brown sugar with molasses;

LJ, light jaggery block; RJ, regular jaggery block; GJ, granulated jaggery; DJ, dark jaggery block (DJ); $\mathrm{CH}$, sugarcane honey. 
Table 2. Total phenol (App.: apparent and Corr.: corrected) and flavonoid content of the 12 sugarcane products studied. Phenol content is given in mg Gallic Acid Equivalents (GAE) and total flavonoids in mg Quercetin Equivalents (QE), per gram of product. Means \pm standard deviations from triplicates.

\begin{tabular}{|c|c|c|c|}
\hline & $\begin{array}{l}\text { App. PHENOL CONTENT } \\
\text { mg GAE/g } / \text { groduct }\end{array}$ & $\begin{array}{l}\text { Corr. PHENOL CONTENT } \\
\text { mg GAE/g } / g_{\text {product }}\end{array}$ & $\begin{array}{c}\text { FLAVONOID CONTENT } \\
\mathrm{mg} \text { QE/g } / \mathrm{g}_{\text {product }}\end{array}$ \\
\hline W & $0.004 \pm 0.001^{\mathrm{a}}$ & $0.0 \pm 0.0^{\mathrm{a}}$ & $0.022 \pm 0.016^{\mathrm{a}}$ \\
\hline $\mathrm{CB}$ & $0.372 \pm 0.009^{\mathrm{b}}$ & $0.371 \pm 0.009^{\mathrm{b}}$ & $0.69 \pm 0.09^{\mathrm{b}}$ \\
\hline DB & $0.42 \pm 0.02^{\mathrm{b}}$ & $0.42 \pm 0.02^{\mathrm{b}}$ & $1.225 \pm 0.015^{\mathrm{c}}$ \\
\hline LB & $0.38 \pm 0.02^{\mathrm{b}}$ & $0.38 \pm 0.02^{\mathrm{b}}$ & $0.85 \pm 0.03^{\mathrm{b}}$ \\
\hline $\mathrm{RB}$ & $0.58 \pm 0.06^{\mathrm{c}}$ & $0.58 \pm 0.06^{\mathrm{c}}$ & $1.25 \pm 0.11^{\mathrm{c}}$ \\
\hline WB & $0.560 \pm 0.016^{\mathrm{c}}$ & $0.546 \pm 0.015^{\mathrm{c}}$ & $1.893 \pm 0.008^{\mathrm{d}}$ \\
\hline MB & $0.81 \pm 0.03^{\mathrm{d}}$ & $0.80 \pm 0.03^{\mathrm{d}}$ & $2.15 \pm 0.03^{\mathrm{d}}$ \\
\hline GJ & $1.76 \pm 0.11^{\mathrm{f}}$ & $1.71 \pm 0.10^{\mathrm{f}}$ & $2.72 \pm 0.10^{\mathrm{e}}$ \\
\hline $\mathrm{LJ}$ & $2.29 \pm 0.13^{\mathrm{g}}$ & $2.18 \pm 0.12^{\mathrm{g}}$ & $3.78 \pm 0.08^{\mathrm{f}}$ \\
\hline RJ & $2.50 \pm 0.12^{\mathrm{h}}$ & $2.33 \pm 0.11^{\mathrm{h}}$ & $3.75 \pm 0.10^{\mathrm{f}}$ \\
\hline DJ & $1.02 \pm 0.04^{\mathrm{e}}$ & $1.00 \pm 0.04^{\mathrm{e}}$ & $1.59 \pm 0.13^{\mathrm{d}}$ \\
\hline $\mathrm{CH}$ & $3.26 \pm 0.16^{\mathrm{i}}$ & $2.62 \pm 0.13^{\mathrm{i}}$ & $6.15 \pm 0.14^{\mathrm{g}}$ \\
\hline
\end{tabular}

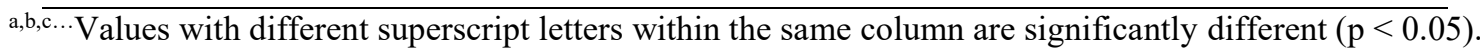
$\mathrm{W}$, white sugar; $\mathrm{CB}$, coated brown sugar; LB, light brown sugar; RB, raw brown sugar; $\mathrm{DB}$, dark brown sugar; WB, wet brown sugar; MB, raw brown sugar with molasses; LJ, light jaggery block; RJ, regular jaggery block; GJ, granulated jaggery; DJ, dark jaggery block (DJ); $\mathrm{CH}$, sugarcane honey. 
Table 3. DPPH and ABTS-TEAC results of samples subjected to thermal treatments. Values \pm standard deviation are given for the six products that exhibited higher AO capacity.

\begin{tabular}{|c|c|c|c|c|c|c|c|}
\hline \multicolumn{8}{|c|}{ DPPH - \% inhibition $(1: 5 \mathrm{w} / \mathrm{v})$} \\
\hline $\begin{array}{c}\text { Temperature } \\
\left({ }^{\circ} \mathrm{C}\right)\end{array}$ & $\begin{array}{l}\text { Time } \\
\text { (min) }\end{array}$ & MB & GJ & $\mathbf{L J}$ & RJ & DJ & $\mathbf{C H}$ \\
\hline- & - & $15.8 \pm 1.2^{\mathrm{a}}$ & $38 \pm 7^{b}$ & $51 \pm 6^{\mathrm{a}}$ & $50 \pm 4^{\mathrm{a}}$ & $22.9 \pm 0.7^{\mathrm{ab}}$ & $75.0 \pm 1.7^{\mathrm{a}}$ \\
\hline 60 & 10 & $13.8 \pm 0.3^{\mathrm{abc}}$ & $44 \pm 3^{\mathrm{a}}$ & $49.7 \pm 1.9^{\mathrm{ab}}$ & $46.0 \pm 1.1^{\mathrm{a}}$ & $17.9 \pm 0.4^{\mathrm{b}}$ & $62.6 \pm 1.1^{\mathrm{ab}}$ \\
\hline 60 & 30 & $13.9 \pm 0.5^{\mathrm{abc}}$ & $35.9 \pm 1.5^{\mathrm{b}}$ & $48.8 \pm 1.7^{\mathrm{ab}}$ & $47.1 \pm 1.2^{\mathrm{a}}$ & $17.3 \pm 0.6^{\mathrm{b}}$ & $62.9 \pm 1.5^{\mathrm{ab}}$ \\
\hline 60 & 60 & $14.7 \pm 0.6^{\mathrm{ab}}$ & $35.25 \pm 1.5^{\mathrm{b}}$ & $48.5 \pm 1.7^{\mathrm{ab}}$ & $44 \pm 3^{\mathrm{a}}$ & $18.9 \pm 0.6^{\mathrm{ab}}$ & $65.1 \pm 1.6^{\mathrm{ab}}$ \\
\hline 80 & 10 & $13.1 \pm 0.5^{\mathrm{bc}}$ & $36.1 \pm 1.1^{\mathrm{b}}$ & $48.4 \pm 1.0^{\mathrm{ab}}$ & $46 \pm 0.9^{\mathrm{a}}$ & $23.4 \pm 0.4^{\mathrm{ab}}$ & $64.3 \pm 1.1^{\mathrm{ab}}$ \\
\hline 80 & 30 & $13.5 \pm 0.4^{\mathrm{abc}}$ & $36.1 \pm 1.0^{\mathrm{b}}$ & $49.4 \pm 1.1^{\mathrm{ab}}$ & $46.1 \pm 1.0^{\mathrm{a}}$ & $21.7 \pm 0.3^{\mathrm{ab}}$ & $54.5 \pm 0.7^{\mathrm{b}}$ \\
\hline 80 & 60 & $14.0 \pm 0.3^{\mathrm{abc}}$ & $36 \pm 2^{b}$ & $48.2 \pm 0.6^{\mathrm{ab}}$ & $45.2 \pm 0.7^{\mathrm{a}}$ & $25.9 \pm 0.2^{\mathrm{a}}$ & $63.3 \pm 1.6^{\mathrm{ab}}$ \\
\hline 100 & 10 & $10.0 \pm 0.2^{\mathrm{d}}$ & $25.1 \pm 0.7^{\mathrm{c}}$ & $43.4 \pm 0.7^{\mathrm{c}}$ & $44.0 \pm 0.5^{\mathrm{a}}$ & $18.7 \pm 0.3^{\mathrm{ab}}$ & $62.0 \pm 0.5^{\mathrm{ab}}$ \\
\hline 100 & 30 & $12.0 \pm 0.3^{\mathrm{cd}}$ & $33.9 \pm 0.9^{\mathrm{b}}$ & $49.2 \pm 0.8^{\mathrm{ab}}$ & $45.5 \pm 0.8^{\mathrm{a}}$ & $20.9 \pm 0.3^{\mathrm{ab}}$ & $68.1 \pm 0.3^{\mathrm{ab}}$ \\
\hline 100 & 60 & $12.5 \pm 0.3^{\mathrm{bcd}}$ & $39.0 \pm 1.0^{\mathrm{ab}}$ & $47.0 \pm 1.0^{\mathrm{b}}$ & $48.6 \pm 0.2^{\mathrm{a}}$ & $22.2 \pm 0.3^{\mathrm{ab}}$ & $55.3 \pm 0.7^{\mathrm{b}}$ \\
\hline \multicolumn{8}{|c|}{ ABTS - $\mu$ mol TEAC } \\
\hline $\begin{array}{c}\text { Temperature } \\
\left({ }^{\circ} \mathrm{C}\right)\end{array}$ & $\begin{array}{l}\text { Time } \\
\text { (min) }\end{array}$ & MB & GJ & $\mathbf{L J}$ & RJ & DJ & $\mathbf{C H}$ \\
\hline- & - & $7.71 \pm 1.2^{\mathrm{a}}$ & $21 \pm 7^{\mathrm{a}}$ & $22 \pm 6^{\mathrm{a}}$ & $24.8 \pm 3.6^{\mathrm{ab}}$ & $7.6 \pm 0.7^{\mathrm{bcd}}$ & $26.9 \pm 1.7^{\mathrm{ab}}$ \\
\hline 60 & 10 & $6.2 \pm 0.3^{\mathrm{c}}$ & $18 \pm 3^{a}$ & $21.0 \pm 1.9^{\mathrm{a}}$ & $21.8 \pm 1.1^{\mathrm{c}}$ & $7.2 \pm 0.4^{\mathrm{cd}}$ & $20.6 \pm 1.0^{\mathrm{d}}$ \\
\hline 60 & 30 & $6.6 \pm 0.5^{\mathrm{bc}}$ & $18.2 \pm 1.5^{\mathrm{a}}$ & $21.7 \pm 1.7^{\mathrm{a}}$ & $24.2 \pm 1.2^{\mathrm{bc}}$ & $7.2 \pm 0.6^{\mathrm{d}}$ & $24.7 \pm 1.5^{\mathrm{c}}$ \\
\hline 60 & 60 & $6.9 \pm 0.6^{\mathrm{abc}}$ & $19.1 \pm 1.5^{\mathrm{a}}$ & $22.2 \pm 1.7^{\mathrm{a}}$ & $27 \pm 3^{\mathrm{ab}}$ & $8.0 \pm 0.6^{b}$ & $26.6 \pm 1.6^{\mathrm{abc}}$ \\
\hline 80 & 10 & $5.2 \pm 0.5^{\mathrm{d}}$ & $18.0 \pm 1.1^{\mathrm{a}}$ & $20.3 \pm 1.0^{\mathrm{a}}$ & $24.2 \pm 0.9^{\mathrm{bc}}$ & $8.0 \pm 0.4^{b}$ & $25.3 \pm 1.1^{\mathrm{bc}}$ \\
\hline 80 & 30 & $6.5 \pm 0.4^{\mathrm{bc}}$ & $18.8 \pm 1.0^{\mathrm{a}}$ & $21.5 \pm 1.1^{\mathrm{a}}$ & $24.9 \pm 1.0^{\mathrm{ab}}$ & $8.0 \pm 0.3^{b}$ & $24.7 \pm 0.7^{\mathrm{c}}$ \\
\hline 80 & 60 & $7.1 \pm 0.3^{\mathrm{ab}}$ & $21 \pm 2^{\mathrm{a}}$ & $22.5 \pm 0.6^{\mathrm{a}}$ & $25.8 \pm 0.7^{\mathrm{ab}}$ & $7.9 \pm 0.2^{\mathrm{bc}}$ & $25.9 \pm 1.6^{\mathrm{bc}}$ \\
\hline 100 & 10 & $6.5 \pm 0.2^{b c}$ & $17.6 \pm 0.7^{\mathrm{a}}$ & $21.2 \pm 0.7^{\mathrm{a}}$ & $24.6 \pm 0.5^{\mathrm{ab}}$ & $8.0 \pm 0.3^{b}$ & $25.6 \pm 0.5^{b c}$ \\
\hline 100 & 30 & $6.8 \pm 0.3^{b c}$ & $18.5 \pm 0.9^{a}$ & $21.9 \pm 0.8^{\mathrm{a}}$ & $24.9 \pm 0.8^{\mathrm{ab}}$ & $8.3 \pm 0.3^{\mathrm{ab}}$ & $26.3 \pm 0.3^{b c}$ \\
\hline 100 & 60 & $7.2 \pm 0.3^{\mathrm{ab}}$ & $20.0 \pm 1.0^{\mathrm{a}}$ & $23.9 \pm 1.0^{\mathrm{a}}$ & $27.1 \pm 0.2^{\mathrm{a}}$ & $8.9 \pm 0.3^{\mathrm{a}}$ & $28.5 \pm 0.7^{\mathrm{a}}$ \\
\hline
\end{tabular}

MB, raw brown sugar with molasses; GJ, granulated jaggery; LJ, light jaggery block; RJ, regular jaggery block; DJ, dark jaggery block; $\mathrm{CH}$, sugarcane honey.

a,b,c, Values with different superscript letters within the same column are significantly different $(\mathrm{p}<0.05)$ 